\title{
Strategi Pengelolaan Pariwisata Pinus Lahendong Di Kota Tomohon
}

\author{
Sandy Andreo Menajang \\ J. A. F. Kalangi \\ Danny D.S Mukuan
}

Jurusan Administrasi Bisnis, Program Studi Administrasi Bisnis

Fakultas Ilmu Sosial dan Politik, Universitas Sam Ratulangi

Email : sandymenajang@gmail.com

\begin{abstract}
The purpose of this research is to know the management strategies of tourism Pine Lahendong and know what are the factors that's encourages and inhibit Pine Lahendong Tourism management strategies. The problem in this research is how Tourism Pinus Lahendong management strategies and what are the factors that inhibit and encourage Tourism Pinus Lahendong management strategies. Tourism is one of the things that are important to a country, the existence of this tourism, then a country or more specifically the Government of the region where it is tourist attraction, will get the infusion of revenues per tourist attractions. The marketing strategy is basically a thorough plan, integrated and fused in the marketing field, which gives guidelines on the activities that will be executed to achieve the marketing goals of a company. Tourism Pinus Lahendong strategy and potential for managed, developed and marketed because it has beautiful natural scenery and a sulfur hot springs into a visitor attraction. This research which means to understand the phenomenon or strengths, weaknesses, opportunities and threats from Tourism Pinus Lahendong holistically with described it in the form of words and language so as to produce a depiction on the phenomenon that happens. the results of the SWOT analysis conducted in the Tourism development of tourism policy, then Pinus Lahendong is improving promotion through various media, to improve the existing facilities in order to provide convenience for visitors and capitalize on potential at once elaborated the opportunities that can be sold and can attract visitors.
\end{abstract}

Keywords : Management strategy, Attractions

\section{Pendahuluan}

Pariwisata merupakan salah satu hal yang penting bagi suatu negara, dengan adanya pariwisata ini, maka suatu negara atau lebih khusus lagi pemerintah daerah tempat objek wisata itu berada, akan mendapatkan pemasukan dari pen-dapatan setiap objek wisata. Pariwisata juga merupakan komoditas yang dibutuhkan oleh setiap individu. Alasannya, karena aktivitas berwisata bagi seorang individu dapat me-ningkatkan daya kreatif, menghilangkan kejenuhan kerja, relaksasi, berbelanja, bisnis, mengetahui pe- 
ninggalan sejarah dan budaya suatu etnik tertentu, kesehatan dan pariwisata spiritualisme.

Sulawesi utara memiliki berbagai macam obyek wisata yang apabila dikelola dan dikembangkan dengan baik dan tepat maka menjadi daerah tujuan wisata yang menarik untuk dikunjungi. Salah satu tempat wisata yang terdapat di Sulawesi utara adalah Wisata Hutan Pinus Lahendong yang terletak di Kelurahan Lahendong Kota Tomohon, dari Pusat Kota Tomohon,

Wisata Hutan Pinus Lahendong berjarak sekitar 3 kilometer menuju arah barat. Tempat ini mudah ditemukan karena melewati jalan utama yang menghubungkan Tomohon dan Kawangkoan di Kabupaten Minahasa, dari Tomohon ke Kawangkoan Wisata Hutan Pinus Lahendong terletak di sisi kanan jalan. Obyek Wisata Pinus Lahendong dengan luas \pm 4 hektar dan ketinggian di atas permukaan laut \pm 700 meter memiliki beberapa fasilitas yaitu, 2 Cafe, 2 Aula, 5 Kamar Penginapan, 14 Kamar Mandi Air Panas belerang, 8 Toilet dan Tempat Parkir. Karena pembangunan yang dilakukan secara bersamaan, maka beberapa tempat seperti cafe dan penginapan belum beroperasi, penataan tempat pun belum sempurna sehingga menimbulkan komplain dari para pengunjung.
Wisata Pinus Lahendong mulai beroperasi pada tahun 2014 dengan biaya karcis masuk Rp.10.000 per orang. Pada tahun 2015 sampai sekarang biaya karcis masuk Wisata Pinus Lahendong Rp. 20.000 per orang, pengunjung sudah mendapatkan paket pisang goreng dan kopi selain itu pengunjung juga bisa menikmati pemandian air panas belerang dengan membayar karcis mandi Rp 5.000 per orang.

Data jumlah pengunjung Wisata Pinus Lahedong

\begin{tabular}{cc}
\hline Tahun & Banyaknya Pengunjung \\
\hline 2014 & 4.560 \\
2015 & 8.295 \\
2016 & 10.440 \\
2017 & 12.600 \\
2018 & 12.780 \\
\hline
\end{tabular}

Dapat di lihat dari tabel bahwa pada tahun 2014 jumlah pengunjung yaitu 4.560 orang, pada tahun 2015 jumlah pengunjung meningkat yaitu 8.295 orang, kemudian tetap terjadi peningkatan pengunjung pada tahun 2016 sebanyak 10.440 orang, pada tahun 2017 jumlah pengunjung tetap mengalami peningkatan dengan jumlah pengunjung sebanyak 12.600 orang dan jumlah pengunjung pada tahun 2018 yaitu 12.780 orang. 
Di kelurahan Lahendong terdapat dua tempat wisata yang menarik yaitu Danau Linow dan Wisata Pinus Lahendong. Walaupun pengunjung Wisata Pinus Lahendong per tahun tetap meningkat, namun dari data empiris yang penulis dapatkan pengunjung Danau Linow per hari lebih banyak dari pada pengunjung Wisata Pinus Lahendong hal ini dikarenakan kurangnya promosi dan penataan tempat yang kalah menarik dari Wisata Pinus Lahendong.

Wisata Pinus Lahendong strategis dan potensial untuk dikelola, dikembangkan dan dipasarkan karena mempunyai pemandangan alam yang indah dan pemandian air panas belerang yang menjadi daya tarik pengunjung. Berdasarkan uraian di atas, penulis tertarik untuk melakukan penelitian tentang Strategi Pengelolaan Pariwisata Pinus Lahendong.

\section{Pariwisata}

Istilah pariwisata terlahir dari bahasa Sansekerta yang komponen-komponennya terdiri dari : "Pari" yang berarti penuh, lengkap, berkeliling; “Wis(man)” yang berarti rumah, properti, kampung, komunitas; dan "ata" berarti pergi terusmenerus, mengembara (roaming about) yang bila dirangkai menjadi satu kata melahirkan istilah pariwisata, berarti : pergi secara lengkap meningggalkan rumah (kampung) berkeliling terus menerus dan tidak bermaksud untuk menetap di tempat yang menjadi tujuan perjalanan (Pendit, 2002).

\section{Strategi pemasaran}

Strategi pemasaran adalah rencana yang menyeluruh, terpadu dan menyatu di bidang pemasaran, yang memberikan panduan tentang kegiatan yang akan dijalankan untuk dapat tercapainya tujuan pemasaran suatu perusahaan (Assauri, 2013).

\section{Pengelolaan}

Pengelolaan adalah salah satu bagian manejemen yang menitik beratkan pada implementasi potensi budaya harus dilaksanakan dengan rentang waktu, berapa langka sistematis yang dapat mengarah pada pencapaian hasil,dan hasil yang dicapai diharapkan pada perencanaan manajeman dengan kegiatan yang sangat spesetif untuk mencapai tujuaan visi, tujuan dan sasaran dari rencana tersebut (Peter Salim dan Yenny Salim, 2002).

\section{Pengembangan Pariwisata}

Pengembangan Pariwisata adalah suatu usaha untuk mengembangkan atau memajukan objek wisata agar objek wisata tersebut lebih baik dan lebih menarik ditinjau dari segi tempat maupun benda- 
benda yang ada di dalamnya untuk dapat menarik minat wisatawan untuk mengunjunginya (Sobari dalam Anindita, 2015).

\section{Analisis SWOT}

Analisis

SWOT dapat mengidentifikasi berbagai faktor secara sistematis untuk merumuskan strategi perusahaan. Analisis ini didasarkan pada logika yang dapat memaksimalkan kekuatan (strengths) dan peluang (opportunities), namun secara bersamaan dapat meminimalkan. Model yang paling popular untuk analisis situasi adalah analisis SWOT (Rangkuti, 2014).

1. Kekuatan (strenght) merupakan sumber atau kemampuan yang dikuasai atau yang tersedia bagi perusahaan dan memberikan keuntungan dibandingkan dengan para pesaingnya dalam melayani kebutuhan para pelanggan.

2. Kelemahan (weakness) merupakan keterbatasan atau kekurangan dalam salah satu sumber daya atau kemampuan (capability) organisasi dibandingkan dengan para pesaingnya yang meciptakan kerugian dalam usaha memenuhi kebutuhan para pelanggan secara efektif.

3. Peluang (opportunities) merupakan situasi yang menguntungkan didalam lingkungan organisasi. cenderungan-kecenderungan yang terdapat di dalam lingkungan yang dapat dimanfaatkan oleh organisasi merupakan sebuah peluang.

4. Ancaman (threats) merupakan situasi utama yang tidak menyenangkan di dalam sebuah lingkungan. Ancaman adalah rintangan utama terhadap posisi saat ini atau posisi yang diinginkan perusahaan atau organisasi.

\section{Metode Penelitian}

Penelitian yang dilakukan merupakan studi kasus yaitu melakukan pengamatan, pengambilan data melalui beberapa teknik pengumpulan data dan menggunakan teknik analisis data yaitu analisis SWOT. Kesimpulan dari penelitian ini hanya berlaku pada Obyek wisata yang diteliti.

Populasi dalam penelitian ini adalah semua orang yang melakukan kegiatan wisata di Obyek Wisata Pinus Lahendong pada tahun 2018. Sampel dalam penelitian ini menggunakan metode insidental random sampling yaitu merupakan teknik penentuan sampel berdasarkan kebetulan /insidental bertemu dengan peneliti dapat digunakan sebagai sampel bila dipandang orang yang ditemui itu cocok sebagai sumber data (Sugiyono, 2007). Untuk mengetahui besarnya ukuran sampel yang akan digunakan dalam penelitian ini, 
digunakan rumus pendekatan slovin (Umar, 2003) sebagai berikut :

$$
\mathrm{n}=\frac{N}{1+N e^{2}}
$$

Dimana :

$\mathrm{n}$ : ukuran sampel

$\mathrm{N}$ : ukuran populasi (Jumlah pengunjung tahun 2018)

e : persen kelonggaran ketidak telitian

karena kesalahan pengambilan sampel yang masih ditolelir (ditetapkan 10\%)

Penelitian ini di laksanakan di Tempat Wisata Pinus Lahendong Tomohon pada Bulan Januari 2019. Informan dalam penelitian ini adalah Manager, Karyawan dan Pengunjung Wisata Pinus Lahendong.

Dalam memperoleh data serta keterangan-keterangan yang diperukan dalam penyusunan skripsi ini, penulis mengadakan riset langsung di lingkungan obyek wisata untuk memperoleh data-data yang diperlukan yaitu melalui :

1. Obsevasi

2. Wawancara

3. Kuesioner

4. Dokumentasi

Dalam penelitian ini metode yang digunakan untuk menjawab strategi pengelolaan obyek wisata Pinus Lahendong yaitu analisis SWOT.

\section{Hasil Penelitian Dan Pembahasan}

Faktor-Faktor Yang Mendorong Strategi Pengelolaan Obyek Wisata Pinus Lahendong
1. Panorama alam yang indah, sejuk dan masih asli

2. Sumber Air Panas Belerang yang Melimpah

3. Kondisi Keamanan yang Baik

4. Suasana Obyek Wisata yang Memberikan Kenyamanan

5. Jarak Tempuh Obyek Wisata yang Dekat dengan Kota.

\section{Faktor-Faktor Penghambat Strategi Pengelolaan Obyek Wisata Pinus Lahendong}

1. Promosi Obyek Wisata yang Masih Kurang

2. Proses Pembangunan yang Lama

3. Kurangnya Tenaga Kerja

\section{Analisis SWOT Sebagai Alat Formulasi Strategi Pengelolaan Wisata Pinus Lahendong}

Tabel Matrik Faktor Internal dan Faktor Eksternal Obyek Wisata Pinus Lahendong

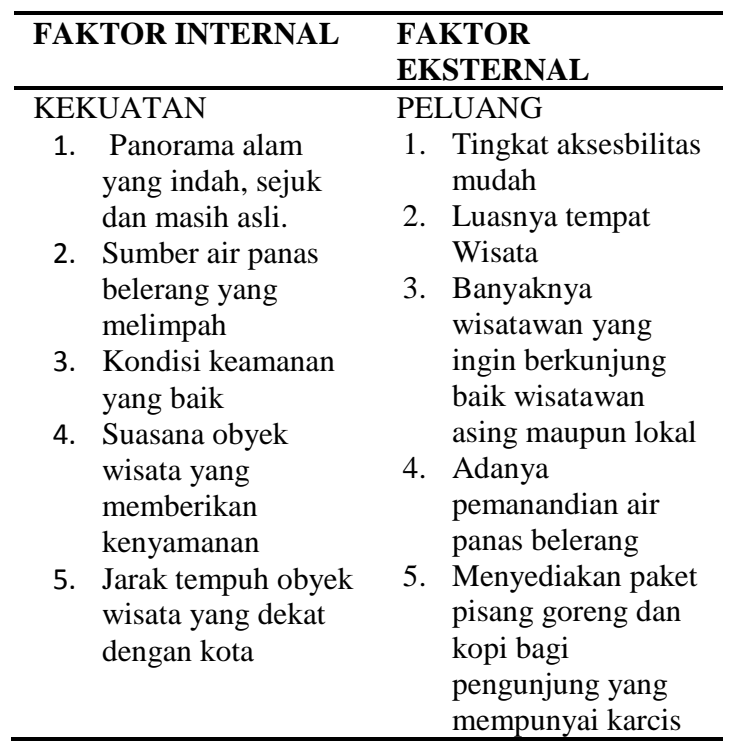




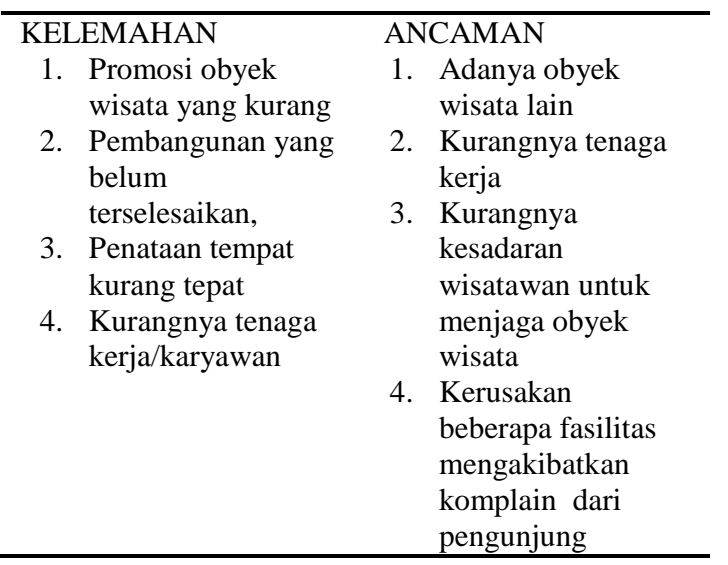

Sumber : Hasil penelitian diolah

Skor tertinggi $(\mathrm{xt}): 4$

Skor terendah $(\mathrm{xr}): 1$

Rumus Rentang : $\mathrm{R}=\mathrm{xt}-\mathrm{xr}$

$$
\begin{aligned}
& R=4-1 \\
& R=3
\end{aligned}
$$

Panjang kelas interval $\mathrm{p}=R / \mathrm{xt}$

$$
\mathrm{p}=0.75
$$

Dengan menggunakan panjang kelas 0,75 dan skor terendah 1 maka dapat dibuat kriteria sebagai berikut :

\begin{tabular}{|c|c|c|c|}
\hline No & Kekuatan & Mean & Ket \\
\hline 1 & $\begin{array}{l}\text { Panorama alam yang } \\
\text { indah, sejuk dan masih } \\
\text { asli }\end{array}$ & 3,54 & $\begin{array}{l}\text { Sangat } \\
\text { Tinggi }\end{array}$ \\
\hline 2 & $\begin{array}{l}\text { Sumber air panas } \\
\text { belerang yang melimpah }\end{array}$ & 3,44 & $\begin{array}{l}\text { Sangat } \\
\text { Tinggi }\end{array}$ \\
\hline 3 & $\begin{array}{l}\text { Kondisi keamanan yang } \\
\text { baik }\end{array}$ & 2,95 & Tinggi \\
\hline 4 & $\begin{array}{l}\text { Suasana obyek wisata } \\
\text { yang memberikan } \\
\text { kenyamanan }\end{array}$ & 3,11 & Tinggi \\
\hline 5 & $\begin{array}{l}\text { Jarak tempuh obyek } \\
\text { wisata yang dekat } \\
\text { dengan kota }\end{array}$ & 3,05 & Tinggi \\
\hline \multicolumn{2}{|c|}{ Mean } & 3,21 & Tinggi \\
\hline
\end{tabular}

\begin{tabular}{llll}
\hline No & Interval & $\begin{array}{l}\text { Kekuatan } \\
\text { dan Peluang }\end{array}$ & $\begin{array}{l}\text { Kelemahan } \\
\text { dan Ancaman }\end{array}$ \\
\hline $\mathbf{1}$ & $3,26-4,00$ & Sangat Tinggi & Sangat Rendah \\
$\mathbf{2}$ & $2,51-3,25$ & Tinggi & Rendah \\
$\mathbf{3}$ & $1,76-2,50$ & Rendah & Tinggi \\
$\mathbf{4}$ & $1,00-1,75$ & Sangat & Sangat Tinggi \\
& & Rendah & \\
\hline
\end{tabular}

1. Mean Kekuatan Obyek Wisata Pinus
2. Mean Kelemahan Obyek Wisata Pinus Lahendong

\begin{tabular}{llll}
\hline No & Kelemahan & Mean & Keterangan \\
\hline $\mathbf{1}$ & $\begin{array}{l}\text { Promosi obyek } \\
\text { wisata yang kurang }\end{array}$ & 1,86 & Tinggi \\
$\mathbf{2}$ & $\begin{array}{l}\text { Pembangunan yang } \\
\text { belum terselesaikan }\end{array}$ & 1,72 & $\begin{array}{l}\text { Sangat } \\
\text { Tinggi }\end{array}$ \\
$\mathbf{3}$ & $\begin{array}{l}\text { Penataan tempat } \\
\text { kurang tepat }\end{array}$ & 2,05 & Tinggi \\
$\mathbf{4}$ & $\begin{array}{l}\text { Kurangnya } \\
\text { Karyawan }\end{array}$ & 2,22 & Tinggi \\
Mean & 1,96 & Tinggi \\
\hline
\end{tabular}

\begin{tabular}{|c|c|c|c|}
\hline No & Peluang & Mean & $\begin{array}{l}\text { Keteranga } \\
\text { n }\end{array}$ \\
\hline 1 & $\begin{array}{l}\text { Tingkat aksesbilitas } \\
\text { mudah }\end{array}$ & 2,94 & Tinggi \\
\hline 2 & Luasnya tempat Wisata & 3,39 & $\begin{array}{l}\text { Sangat } \\
\text { Tinggi }\end{array}$ \\
\hline 3 & $\begin{array}{l}\text { Banyaknya wisatawan } \\
\text { yang ingin berkunjung } \\
\text { baik wisatawan asing } \\
\text { maupun local }\end{array}$ & 2,94 & Tinggi \\
\hline 4 & $\begin{array}{l}\text { Adanya pemanandian } \\
\text { air panas belerang }\end{array}$ & 3,38 & $\begin{array}{l}\text { Sangat } \\
\text { Tinggi }\end{array}$ \\
\hline 5 & $\begin{array}{l}\text { Menyediakan paket } \\
\text { pisang goreng dan kopi } \\
\text { bagi pengunjung yang } \\
\text { mempunyai karcis }\end{array}$ & 3,40 & $\begin{array}{l}\text { Sangat } \\
\text { Tinggi }\end{array}$ \\
\hline \multicolumn{2}{|c|}{ Mean } & 3,21 & Tinggi \\
\hline
\end{tabular}

3. Mean Peluang Obyek Wisata Pinus Lahendong

\begin{tabular}{|c|c|c|c|}
\hline No & Ancaman & Mean & Keterangan \\
\hline 1 & $\begin{array}{l}\text { Adanya obyek } \\
\text { wisata lain }\end{array}$ & 1,3 & $\begin{array}{l}\text { Sangat } \\
\text { Rendah }\end{array}$ \\
\hline 2 & $\begin{array}{l}\text { Kurangnya tenaga } \\
\text { kerja }\end{array}$ & 2,0 & Rendah \\
\hline 3 & $\begin{array}{l}\text { Kurangnya } \\
\text { kesadaran } \\
\text { wisatawan untuk } \\
\text { menjaga obyek } \\
\text { wisata }\end{array}$ & 2,94 & Rendah \\
\hline 4 & $\begin{array}{l}\text { Kerusakan } \\
\text { beberapa fasilitas } \\
\text { Obyek Wisata }\end{array}$ & 2,20 & Rendah \\
\hline \multicolumn{2}{|c|}{ Mean } & 2,63 & Rendah \\
\hline
\end{tabular}

4. Mean Ancaman Wisata Pinus Lahendong

Tabel Faktor Strategis Internal Obyek Wisata Pinus Lahendong

\begin{tabular}{lccc}
\hline Faktor Strategis Internal & Bobot & Rating & $\begin{array}{c}\text { Skor } \\
\text { (Bobot x } \\
\text { Rating) }\end{array}$ \\
\hline $\begin{array}{l}\text { Kekuatan } \\
\text { Panorama alam yang } \\
\text { indah, sejuk dan }\end{array}$ & 0,1478 & 4 & 0,5912 \\
\hline
\end{tabular}


masih asli

- Sumber air panas

0,1436

4

0,5744

belerang yang

melimpah

- Kondisi keamanan

0,1232

3

0,3696

yang baik

- Suasana obyek

$0,1299 \quad 3$

0,3897

wisata yang

memberikan

kenyamanan

- Jarak tempuh obyek

$0,1274 \quad 3$

0.3822

wisata yang dekat dengan kota

Jumlah Skor Kekuatan

Kelemahan

- Promosi obyek wisata yang kurang

- Pembangunan yang belum terselesaikan

- Penataan tempat kurang tepat

- Kurangnya Karyawan

- Jumlah Skor

Kelemahan

Jumlah Keseluruhan

\begin{tabular}{ccc}
0,0776 & 2 & 0.1552 \\
0,0718 & 1 & 0,0718 \\
0,0856 & 2 & 0,1712 \\
0,0927 & 2 & 0,1854 \\
& & 0,5836 \\
1 & & 2.8907 \\
\hline
\end{tabular}

Berdasarkan tabel diatas dapat diketahui bobot dan rating faktor strategis internal Obyek Wisata Pinus Lahendong dimana pembobotan dilakukan dengan tujuan faktor- faktor tersebut dapat memberikan dampak terhadap faktor strategis. Pembobotan dalam faktor-faktor strategis Obyek Wisata Pinus Lahendong diperoleh dari bobot $=m x / m t, m x:$ mean dari faktor $\mathrm{x}$ dan $\mathrm{mt}$ : mean total faktor strategis internal. Sedangkan tujuan rating adalah memberikan skala mulai dari 4 sampai 1 berdasarkan pengaruh faktor tersebut terhadap pengembangan Obyek Wisata Pinus Lahendong, dan untuk skor pembobotan untuk memperoleh total skor pembobotan Obyek Wisata Pinus Lahendong. Nilai total ini menunjukkan bagaimana Obyek Wisata Pinus Lahendong bereaksi terhadap faktor-faktor strategis internalnya.

Tabel Faktor Strategis Eksternal Obyek Wisata Pinus Lahendong

\begin{tabular}{|c|c|c|c|}
\hline $\begin{array}{l}\text { Faktor Strategis } \\
\text { Eksternal }\end{array}$ & Bobot & Rating & $\begin{array}{c}\text { Skor } \\
\text { (Bobot x } \\
\text { Rating) } \\
\end{array}$ \\
\hline $\begin{array}{l}\text { Peluang } \\
\text { - Tingkat } \\
\text { aksesbilitas } \\
\text { mudah }\end{array}$ & 0,1200 & 3 & 0,36 \\
\hline $\begin{array}{l}\text { - Luasnya tempat } \\
\text { Wisata }\end{array}$ & 0,1384 & 4 & 0,5536 \\
\hline 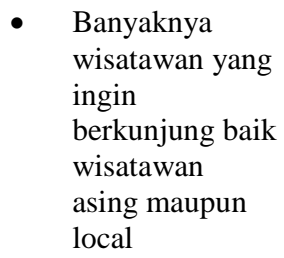 & 0,1200 & 3 & 0,36 \\
\hline $\begin{array}{l}\text { Adanya } \\
\text { pemanandian } \\
\text { air panas } \\
\text { belerang }\end{array}$ & 0,1380 & 4 & 0,5520 \\
\hline $\begin{array}{l}\text { Menyediakan } \\
\text { paket pisang } \\
\text { goreng dan kopi } \\
\text { bagi } \\
\text { pengunjung } \\
\text { yang } \\
\text { mempunyai } \\
\text { karcis }\end{array}$ & 0,1388 & 4 & 0,5552 \\
\hline $\begin{array}{l}\text { Jumlah Skor } \\
\text { Peluang } \\
\text { Ancaman }\end{array}$ & & & 2,3808 \\
\hline $\begin{array}{l}\text { - Adanya obyek } \\
\text { wisata lain }\end{array}$ & 0,0530 & 1 & 0,053 \\
\hline $\begin{array}{l}\text { Kurangnya } \\
\text { tenaga kerja }\end{array}$ & 0,0816 & 2 & 0,1632 \\
\hline $\begin{array}{l}\text { - Kurangnya } \\
\text { kesadaran } \\
\text { wisatawan } \\
\text { untuk menjaga } \\
\text { obyek wisata }\end{array}$ & 0,1200 & 3 & 0,36 \\
\hline $\begin{array}{l}\text { - Kerusakan } \\
\text { beberapa } \\
\text { fasilitas Obyek } \\
\text { Wisata }\end{array}$ & 0,0898 & 2 & 0,1796 \\
\hline $\begin{array}{l}\text { Jumlah skor } \\
\text { ancaman }\end{array}$ & & & 0,7558 \\
\hline $\begin{array}{l}\text { Jumlah } \\
\text { Keseluruhan }\end{array}$ & & & 3,1366 \\
\hline
\end{tabular}

Berdasarkan perhitungan yang dilakukan melalui analisis SWOT, diperoleh nilai akhir dari kekuatan, kelemahan, peluang, 
dan ancaman seperti terlihat pada tabel berikut :

Rekapitulasi Hasil Perhitungan Kekuatan, Kelemahan, Peluang, dan Ancaman

\begin{tabular}{|c|c|c|}
\hline No. & Uraian & Nilai \\
\hline & Faktor Internal & \\
\hline & $\begin{array}{ll}\text { - } & \text { Kekuatan } \\
\text { - } & \text { Kelemahan }\end{array}$ & $\begin{array}{l}2,30 \\
0,58\end{array}$ \\
\hline
\end{tabular}

2. Faktor Eksternal

$\begin{array}{lll}\text { - Peluang } & 2,38 \\ \text { - } & \text { Ancaman } & 0,75\end{array}$

Kekuatan - Kelemahan (Faktor Internal) : 2,30-0,58 =1,72

Peluang - Ancaman (Faktor Eksternal) : 2,38 - 0,75 = 1.63

Apabila nilai-nilai tersebut dimasukkan dalam Matrix Grand Strategy terlihat posisi pengembangan sektor pariwisata di Obyek Wisata Pinus Lahendong berada di posisi Strategi Pertumbuhan, yaitu memanfaatkan seoptimal mungkin kekuatan dan peluang yang dimiliki.

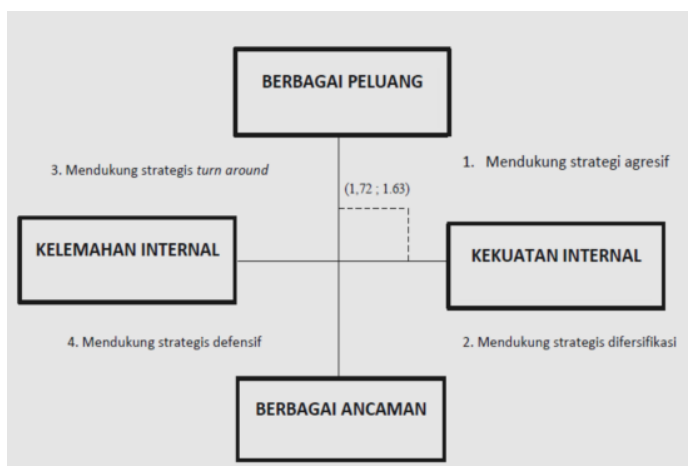

Gambar Matrix Grand Strategy Obyek Wisata Pinus Lahendong

Strategi yang dapat diterapkan dalam kondisi ini adalah mendukung kebijakan yang agresif (growth oriented strategy). Dari analisis SWOT menghasilkan empat (4) kemungkinan strategi alternative, yaitu :

\section{Strategi SO (Strength and} Opportunities), yaitu strategi yang mengoptimalkan kekuatan (strength) untuk memanfaatkan peluang (Opportunities), ialah :

a. Mengelola potensi obyek wisata yang dimiliki (panorama alam yang indah, sejuk dan masih asli, sumber air panas belerang yang melimpah, suasana obyek wisata yang memberikan kenyamanan dan lokasi dekat dengan pusat kota Tomohon sehingga mudah untuk ditemukan)

b. Meningkatkan keamanan Obyek Wisata Pinus Lahendong, menjaga kenyamanan dan menarik pengunjung.

2. Strategi WO (Weaknesses and Opportunities), yaitu strategi yang meminimalkan kelemahan (weaknesses) untuk memanfaatkan peluang (opportunities), ialah :

a. Luasnya tempat Wisata Pinus Lahendong dapat menjadi peluang untuk pengelolaan kedepan.

b. Pemanandian air panas belerang merupakan peluang yang besar karena memiliki ketertarikan tersendiri bagi para pengunjung.

c. Mempunyai cafe dimana setelah pengunjung mendapatkan karcis masuk, karcis tersebut dapat ditukarkan dengan secangkir kopi dan paket pisang goreng. Hal ini merupakan bagian strategi yaitu promosi untuk meningkatkan para pengunjung. 
3. Strategi ST (Strength and Threats), yaitu strategi yang menggunakan kekuatan (strength) untuk mengatasi ancaman (threats), ialah :

a. Kondisi keamanan obyek wisata yang baik memberikan kenyamanan bagi pengunjung lingkungan.

b. Pembangunan di selesaikan segera agar semua fasilitas dapat berjalan semestinya sehingga terhindar dari komplein pengunjung.

4. Strategi WT (Weaknesses and Threats), yaitu strategi yang meminimalkan kelemahan (weaknesses) dan menghindari ancaman (threats), ialah :

a. Meningkatkan promosi dan memperbaiki fasilitas yang ada agar lebih bagus untuk menarik pengunjung sehingga siap untuk menghadapi persaingan antar obyek wisata.

b. Melakukan penambahan tenaga kerja dalam obyek wisata sehingga mempercepat perbaikan fasilitas yang rusak dan yang belum dibangun.

Untuk itu kebijakan pengembangan pariwisata Obyek Wisata Pinus Lahendong adalah :

1. Meningkatkan promosi mengenai Obyek Wisata Pinus Lahendong melalui berbagai media baik media cetak maupun elektronik, mengikuti pameran-pameran wisata yang ada agar lebih dikenal masyarakat.
2. Memperbaiki fasilitas yang ada seperti perbaikan cafe, penginapan, tempat mandi dan jalan yang rusak sehingga menarik dan memberikan kenyamanan bagi pengunjung.

3. Memanfaatkan potensi yang dimiliki Obyek Wisata Pinus Lahendong yaitu sumber air panas belerang yang melimpah sekaligus megembangkan peluang yang dapat dijual dan dapat menarik pengunjung.

\section{Matriks SWOT Analisis Lingkungan Internal dan Lingkungan Eksternal Pariwisata Obyek Wisata Pinus Lahendong}

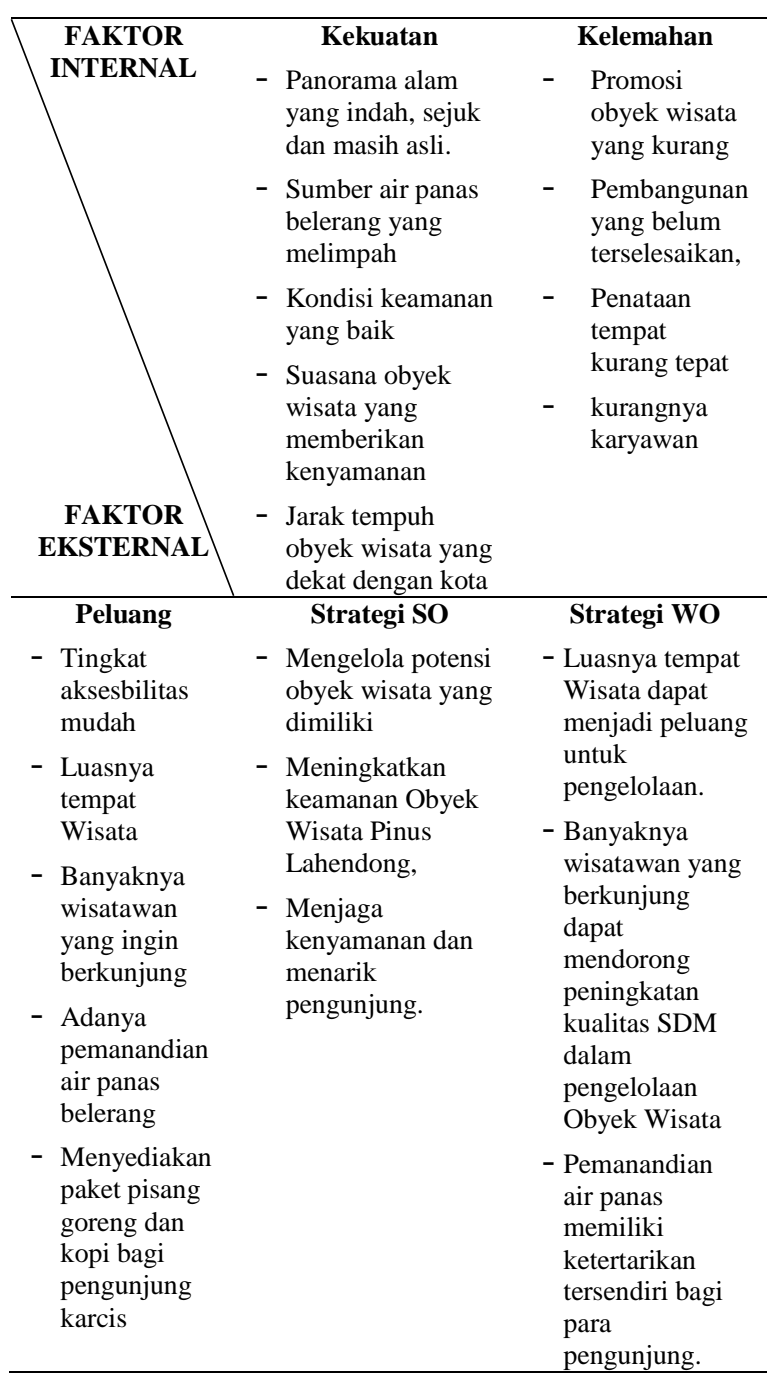


- Pengunjung mendapatkan karcis masuk yang dapat ditukarkan dengan kopi dan pisang goreng.

\begin{tabular}{lll}
\hline Ancaman & Strategi ST & Strategi WT \\
- Adanya & - Panorama alam & - Meningkatkan \\
obyek wisata & yang indah, sejuk, & promosi dan \\
lain & dan suasana yang & memperbaiki \\
- Kurangnya & memberikan & fasilitas yang \\
tenaga kerja & kenyamanan maka & sehingga siap \\
- Kurangnya & pengunjung tidak & untuk \\
kesadaran & akan bosan dalam & menghadapi \\
wisatawan & berkunjung. & persaingan antar \\
untuk & Kondisi keamanan & obyek wisata. \\
menjaga & yang baik & - Melakukan \\
obyek wisata & memberikan & penambahan \\
- Kerusakan & kenyamanan bagi & tenaga kerja \\
beberapa & pengunjung & sehingga \\
fasilitas & - Sumber-sumber & mempercepat \\
mengakibatka & daya yang & perbaikan \\
n komplain & dikembangkan & fasilitas yang \\
dari & secara hati-hati dan & rusak dan yang \\
pengunjung & diupayakan tidak & belum \\
& merusak & dibangun. \\
& lingkungan. & - Penataan yang \\
& - Pembangunan di & baik sehingga \\
& selesaikan segera & meningkatkan \\
& agar semua & kesadaran \\
fasilitas dapat & untuk menjaga \\
& berjalan. & wisata \\
\hline
\end{tabular}

\section{Kesimpulan}

Hasil penelitian melalui analisis SWOT dengan mengidentifikasi faktor kekuatan, kelemahan, peluang dan ancaman, yaitu sebagai berikut:

\section{Kekuatan yang dimiliki Wisata Pinus} Lahendong yaitu Panorama alam yang indah, sejuk dan masih asli, sumber air panas belerang yang melimpah, kondisi keamanan yang baik, suasana obyek wisata yang memberikan kenyamanan dan memiliki jarak tempuh obyek wisata yang dekat dengan kota

Kelemahan yang dimiliki Wisata Pinus Lahendong yaitu promosi obyek wisata yang kurang, pembangunan yang belum terselesaikan, penataan tempat kurang tepat dan kurangnya tenaga kerja/karyawan

Peluang yang dimiliki Wisata Pinus Lahendong yaitu tingkat aksesibilitas mudah, luasnya tempat Wisata, banyaknya wisatawan yang ingin berkunjung baik wisatawan asing maupun lokal, adanya pemandian air panas belerang, menyediakan paket pisang goreng dan kopi bagi pengunjung yang mempunyai karcis

Ancaman yang dimiliki Wisata Pinus Lahendong yaitu adanya obyek wisata lain, kurangnya tenaga kerja, kurangnya kesadaran wisatawan untuk menjaga obyek wisata dan kerusakan beberapa fasilitas mengakibatkan komplain dari pengunjung

Dari hasil analisis maka kebijakan pengembangan pariwisata Obyek Wisata Pinus Lahendong adalah meningkatkan promosi Obyek Wisata Pinus Lahendong melalui berbagai media, memperbaiki fasilitas yang ada agar dapat memberikan kenyamanan bagi pengunjung dan memanfaatkan potensi yang dimiliki Obyek Wisata Pinus Lahendong sekaligus mengembangkan peluang yang dapat dijual dan dapat menarik pengunjung.

\section{Saran}

Promosi tempat Wisata Pinus Lahendong masih tergolong kurang evektif, untuk itu perlu ditingkatkan lagi yaitu 
dengan menggunakan media cetak seperti, Koran, Majalah, Brosur, Poster dan sebagainya.

Mempercepat proses pembangunan obyek wisata demi meningkatkan kualitas dan meningkatkan jumlah pengunjung pada obyek wisata tersebut.

Dilakukan penambahan Tenaga Kerja di Tempat Wisata Pinus Lahendong untuk menunjang pelayanan yang baik dari tempat ini.

Pengelola Wisata Pinus Lahendong harus memanfaatkan sebaik mungkin potensi yang ada, sehingga dapat menghadapi persaingan dengan objekobjek wisata lainnya dan dapat meningkatkan jumlah pengunjung.

\section{Daftar Pustaka}

Assauri, S. 2013. Managemen Pemasaran. Jakarta : Rajawali Pers.

Pendit ,S. 2002 : Ilmu Pariwisata Sebuah Pengantar Perdana. Jakarta : Pradya Paramita.

Rangkuti, F. 2009 : Analisis SWOT: Teknik Membedah Kasus Bisnis, Edisi 16. Jakarta: PT.Gramedia Pustaka Utama.

Sobri, dkk. 2009. Pengelolaan Pendidikan. Yogyakarta: Multi Pressindo.

Sutopo. 2002. Pengantar Penelitian Kualitatif. Surakarta : Universitas Sebelas Maret Press.

Sinaga, Supriono. 2010 : Potensi dan Pengembangan Objek Wisata Di Kabupaten Tapanuli Tengah. Kertas Karya. Program DIII Pariwisata. Universitas Sumatera Utara.
Yuwana, S . 2010 : Analisis Permintaan Kunjungan Objek Wisata Kawasan Dataran Tinggi Dieng Kabupaten Banjarnegara (Skripsi). Universitas Diponegoro. 